\title{
Alcohol use behaviors and risk of metabolic syndrome in South Korean middle-aged men
}

\author{
Jinhee Kim', Su-Kyung Chu ${ }^{2 *}$, Kyungjoo Kim ${ }^{3}$ and Ju-Ryoung Moon ${ }^{4}$
}

\begin{abstract}
Background: It is thought that small volumes of alcohol may have positive effects on health. However, excessive drinking results in serious health problems. An accurate method to determine individual alcohol use behaviors are needed to assess objectively the extent to which drinking affects health. This study investigated the association between risk of metabolic syndrome (MetS) and alcohol use behaviors in middle-aged South Korean men using the Alcohol Use Disorders Identification Test.

Methods: This study used data from the South Korea National Health and Nutrition Examination (KNHANES) IV (2008), which extracted the standard survey household by using the proportional systematic sampling method. Data of 714 participants from KNHANES IV, 2008 were analyzed using Surveyfreq and Surveylogistic regression to investigate the association between MetS and alcohol use behaviors in middle-aged South Korean men.

Results: After adjustment for education, smoking, and physical activity, alcohol use behaviors were significantly associated with an increased risk of hypertension [odds ratio $(\mathrm{OR})=2.54,95 \%$ confidence interval $(\mathrm{Cl})=1.5-4.06$ in the hazardous group; $\mathrm{OR}=2.99,95 \% \mathrm{Cl}=1.84-4.92$ in the problem group]; impaired fasting glucose $(\mathrm{OR}=2.15$, $95 \% \mathrm{Cl}=1.16-3.99$ in the hazardous group; $\mathrm{OR}=2.48,95 \% \mathrm{Cl}=1.42-4.33$ in the problem group); dyslipidemia (OR $=2.19,95 \% \mathrm{Cl}=1.38-3.47$ in the problem group); abdominal obesity $(\mathrm{OR}=1.93,95 \% \mathrm{Cl}=1.17-3.19$ in the hazardous group; $\mathrm{OR}=1.85,95 \% \mathrm{Cl}=1.17-2.92$ in the problem group); and MetS (OR $=2.16,95 \% \mathrm{Cl}=1.24-3.77$ in the hazardous group; $\mathrm{OR}=2.54,95 \% \mathrm{Cl}=1.41-4.58$ in problem group).

Conclusions: This study found that excessive alcohol use behaviors increased the risk of hypertension, diabetes, dyslipidemia, abdominal obesity, and MetS. Considering the rising rate of alcohol consumption and heavy drinking at single sittings, a culture of less risky alcohol consumption must be established to promote health among middle-aged men.
\end{abstract}

\section{Background}

Middle-aged men can experience a sense of crisis and anxiety along with a deterioration of their physical health. This deterioration may be the result of attempting to perform a number of demanding roles, which may include parenting dependent children, providing care to aging relatives, and paid work [1]. In South Korea, before the 1980s, it was not expected that men would have much to do with the day-to-day care of their families. However, as societal values have shifted to emphasize individual quality of life, South Korean men have come to recognize their roles within the family as well as in the workplace [2]. However, this shift may

\footnotetext{
* Correspondence: chusu@eulji.ac.kr

${ }^{2}$ Department of Nursing, Eulji University, Seoul, South Korea

Full list of author information is available at the end of the article
}

have also increased the psychological pressure and sense of conflict felt within the middle-aged group, causing more stress, drinking, and chronic fatigue [3].

Previously known as $\mathrm{X}$-syndrome or insulin resistance syndrome, metabolic syndrome (MetS) is a pathological condition characterized by diabetes, impaired glucose tolerance, dyslipidemia, hypertension, and obesity, and it contributes to the risk of death caused by cardiovascular disease and diabetes. Thus, early detection and management of this pathological condition are needed [4-6]. The prevalence of MetS differs among studies, but is generally in the range $8-24 \%$ in men and $7-46 \%$ in women [7]; the prevalence in South Korea has been reported as $27.4 \%$ in men and $20.9 \%$ in women $(24.1 \%$ in South Korean adults) [8].

\section{(Ciomed Central}


It is thought that small volumes of alcohol may have positive effects on health [9]. However, excessive drinking results in serious health problems, including an increased risk of cardiovascular disease, cancer, liver cirrhosis, chronic pancreatitis, and violence [10-12]. Alcohol-related health problems are of particular concern in South Korea, where the easy availability of alcohol and a tolerant and widespread "drinking culture" facilitate excessive consumption [13].

A large body of research has consistently shown that the pathogenesis of MetS is the result of factors related to both lifestyle (e.g., smoking, physical activity, and diet) and heredity [14-20]. However, studies examining the contribution of alcohol consumption to MetS have reported conflicting results [21-24]. This inconsistency was assumed to be derived from unreliable estimates of alcohol consumption, based on self-reported frequency of drinking and average daily alcohol consumption [25].

An accurate method to determine individual alcohol use behaviors are needed to assess objectively the extent to which drinking affects health. In addition, rather than relying upon simple variables, such as average frequency and daily consumption of alcohol, it necessary to assess the individual's alcohol use behaviors, which include alcohol-related health problems and symptoms of alcohol dependence.

Our study investigated the association between the risk of MetS and alcohol use behaviors in middle-aged South Korean men using the Alcohol Use Disorders Identification Test (AUDIT), developed by the World Health Organization (WHO)[26].

\section{Methods}

Study design

This cross-sectional study investigated the association between the risk of MetS and alcohol use behaviors in 40-50-year-old South Korean men.

\section{Data source and ethical considerations}

Data from the second year of the fourth South Korean National Health and Nutrition Examination Survey (KNHANES IV) were used to investigate the association between the risk of MetS and alcohol use behaviors. KNHANES is a national survey performed every three years, beginning in 1998; it replaces the Korean National Health and Health Behavior Survey that were carried out every 3 years from 1962 to 1983 and the Korean National Nutrition Survey that was carried out every year from 1969 to 1995 . The purpose of KNHANES is to establish national health policy and to develop a knowledge base for the evaluation of health risk factors and health indicators. The fourth survey, which was initiated in 2007, was later converted into a year-round investigation to improve weaknesses in survey items and the quality of results gained. The first (2007) and second (2008) years of KNHANES IV completed.

The KNHANES IV data (2008) extracted the standard survey household by using a systematic sampling method that was proportional to the number of households after the first stratified sampling conducted considering the region, administration district, and type of residence (apartment or regular house). Although the stratification variables were not considered, sex, and age range of the population were considered as the domain variables. KNHANES IV (2008) consisted of a Health Interview, Health Behavior Surveys, Health Examination Study, and Nutrition Survey. More details on the research methodology used to gather and analyze the second-year KNHANES IV data (2008) are available from the Guidelines for Use of KNHANES IV Raw Data [27] and Final Report of KNHANES IV Sampling Frame [28]. Raw data were requested directly from the KNHANES research group.

The National Evidence-based Healthcare Collaborating Agency (NECA) ethics committee approved the study.

\section{Study population}

This study examined survey responses from 1,146 middleaged men (40-59 years of age) who completed the Health Interview, Health Behavior Surveys, and Health Examination Study for KNHANES IV. However, we excluded 432 men whose documentation showed missing values for important analytical variables, as well as those who had been diagnosed and treated for hypertension and diabetes, leaving a total of 714 participants in this study.

\section{Measures \\ General characteristics}

The general individual characteristics examined in our study included age, co-habitation, education, monthly average household income, smoking, and physical activity. Middle-aged men were split into two categories (4049 and 50-59 years). Co-habitation referred to whether the individual lived with a spouse. Educational attainment was categorized as follows: no schooling, elementary school, middle school, high school, and college or post-graduate. Household income was categorized into low ( $<1,290$ thousand won), middle (1,300-3,390 thousand won), and high ( $>3,400$ thousand won) income classes, which has been recommended by other agencies [29]; these figures are based on the 2008 national monthly average income of 3,370 thousand won for households with more than two people and a minimum monthly living expense of 1,270 thousand won for a family of four people [29,30]. Regarding smoking, participants were categorized into nonsmokers with no past smoking experience, ex-smokers, and current smokers [23]. Physical activity was assessed on a yes/no basis, 
where "exercise" meant moderate activity for more than 30 minutes on 5 days per week or intense activity for more than 20 minutes on 3 days per week [31], or walking more than 30 minutes a day for more than 5 days per week.

\section{Alcohol use behaviors}

Individual alcohol use behaviors were categorized according to AUDIT score. AUDIT is a simple tool, developed by the WHO, to identify alcohol use behaviors in a primary care setting. The main items on this instrument are recent alcohol use, alcohol dependence symptoms, and alcohol-related problems. The test is made up of 10 questions summing to scores of 0 to 40 ; that is, each question has a set of possible responses, and each response has a score ranging from 0 to 4 . Scores in the range of 0-7 represented low-risk drinking, 8-15 represented a medium-level alcohol problem, and scores of $\geq 16$ represented a high-level alcohol problem[26]. This study categorized alcohol use into normal use (0-7), hazardous use (8-15), and problem group (16-40).

\section{MetS}

Based on guidance given in the National Cholesterol Education Program Adult Treatment Panel [32] and the Western Pacific Region's Asian Pacific Guideline[33], we defined MetS as satisfying three or more of the following criteria: (i) presence of hypertension, as determined by systolic blood pressure $\geq 130 \mathrm{mmHg}$ or diastolic blood pressure $\geq 85 \mathrm{mmHg}$; (ii) fasting plasma glucose $\geq 110 \mathrm{mg} / \mathrm{dL}$; (iii) serum triglyceride levels $\geq 150 \mathrm{mg} /$ $\mathrm{dL}$; (iv) serum high density lipoprotein (HDL) $<40 \mathrm{mg} /$ $\mathrm{dL}$; or (v) waist circumference $>90 \mathrm{~cm}$.

\section{Statistical analyses}

Considering the fact that the KNHANES IV data (2008) were extracted by the stratified sampling method, analyses were done using a survey procedure. Surveyfreq was used to compare differences in general characteristics, each of the MetS components, and the prevalence and number of MetS components according to alcohol use behaviors. Survey logistic regression was used to estimate the magnitude of the association between alcohol use behaviors and risk of MetS and each of its components. Data were adjusted for education, smoking, and physical activity. To test for a linear dose-response relationship, we scored the categories of alcohol use behaviors and entered the score as a continuous term in the regression model. Differences were considered statistically significant at $P<0.05$. All analyses were performed using SAS version 9.2 (SAS Institute, Inc., Cary, NC, USA).

\section{Results}

When classified according to alcohol consumption group, the participants showed significant differences according to educational attainment, smoking, and physical activity. The highest level of educational attainment was high school for most men in the normal (40.0\%), hazardous (42.8\%), and problem (36.1\%) groups, but significant differences existed among these three groups $(p=0.038)$. Significant differences also existed with respect to smoking habits, with current smokers forming the largest part of the normal group (42.1\%) compared to ex-smokers in the hazardous (51.8\%) and problem $(60.8 \%)$ groups $(p<0.001)$. Most men within the normal $(79.1 \%)$, hazardous $(84.5 \%)$, and problem (72.6\%) groups reported that they did not exercise regularly, with significant statistical differences among the three groups ( $p=0.006$; Table 1$)$.

Categorization according to alcohol use behaviors also revealed significant differences in the components of MetS, with significant differences in blood pressure, fasting plasma glucose, triglyceride levels, and waist circumference among the groups. The proportion of hypertensive subjects differed significantly among the normal (19.7\%), hazardous (39.7\%), and problem (41.3\%) groups $(p<0.001)$, as did fasting plasma glucose levels (normal, 9.1\%; hazardous, 17.4\%; problem, 19.8\%; $p=$ 0.011 ), triglyceride levels (normal, $37.1 \%$; hazardous, 46.2\%; problem, $56.5 \%$; $p=0.002$ ), and waist circumferences (normal, 19.1\%; hazardous, 31.3\%; problem, 29.0\%; $p=0.016)$. Overall, fewer men in the normal group (19.0\%) were diagnosed with MetS, as compared to the hazardous $(19.0 \%)$ and problem $(21.3 \%)$ groups ( $p=$ 0.009; Table 2).

Significant statistical differences were also observed in the number of concurrent risk factors according to alcohol use behaviors $(p<0.001)$. Within the normal group, most men showed zero $(39.7 \%)$ or one $(36.3 \%)$ risk factor, followed by a much smaller proportion experiencing two (14.0\%). This distribution shifted upward in the hazardous group, with $26.9 \%$ showing zero factors, $25.8 \%$ showing one, and $28.3 \%$ showing two. This was similar in the problem group, with $20.2 \%$ of men showing zero factors, $32.0 \%$ showing one, and $26.5 \%$ showing two (Table 3).

After adjustment for education, smoking, and physical activity, alcohol use behaviors were significantly associated with an increased risk of hypertension [odds ratio $(\mathrm{OR})=2.54,95 \%$ confidence interval $(\mathrm{CI})=1.59-4.06$ in the hazardous group; $\mathrm{OR}=2.99,95 \% \mathrm{CI}=1.84-4.92$ in the problem group]; impaired fasting glucose $(\mathrm{OR}=$ $2.15,95 \% \mathrm{CI}=1.16-3.99$ in the hazardous group; $\mathrm{OR}=$ $2.48,95 \% \mathrm{CI}=1.42-4.33$ in the problem group); dyslipidemia $(\mathrm{OR}=2.19,95 \% \mathrm{CI}=1.38-3.47$ in the problem group); abdominal obesity $(\mathrm{OR}=1.93,95 \% \mathrm{CI}=1.17$ 3.19 in the hazardous group; $\mathrm{OR}=1.85,95 \% \mathrm{CI}=1.17$ 2.92 in the problem group); and MetS (OR $=2.16,95 \%$ $\mathrm{CI}=1.24-3.77$ in the hazardous group; $\mathrm{OR}=2.54,95 \%$ $\mathrm{CI}=1.41-4.58$ in problem group). Additionally, a dose- 
Table 1 Characteristics of study participants according to alcohol use behaviors groups

\begin{tabular}{|c|c|c|c|c|c|c|c|}
\hline \multirow[t]{2}{*}{ Variables } & \multicolumn{3}{|c|}{ Normal* } & \multicolumn{2}{|l|}{ Hazardous* } & \multicolumn{2}{|l|}{ Problem* } \\
\hline & $\begin{array}{r}\text { Unweighted } \\
(\mathrm{n}=219) \\
\end{array}$ & Weighted & $\begin{array}{r}\text { Unweighted } \\
(n=263) \\
\end{array}$ & Weighted & $\begin{array}{r}\text { Unweighted } \\
(\mathrm{n}=232)\end{array}$ & Weighted & \\
\hline Age (yr) & & & & & & & .827 \\
\hline $40-49$ & $137(62.6)$ & $1,012,233(67.4)$ & $164(62.4)$ & $1,185,640(64.6)$ & $147(63.4)$ & $1,039,470(66.8)$ & \\
\hline $50-59$ & $82(37.4)$ & $488,847(32.6)$ & 99 (37.6) & $649,358(35.4)$ & 85 (36.6) & $516,329(33.2)$ & \\
\hline Cohabitation & & & & & & & .494 \\
\hline Yes & $202(92.2)$ & $1,380,253(92.0)$ & $240(91.3)$ & 1,684,197 (91.8) & $203(87.5)$ & $1,384,220(89.0)$ & \\
\hline No & $17(7.8)$ & $120,827(8.0)$ & $23(8.7)$ & $150,801(8.2)$ & $29(12.5)$ & $171,578(11.0)$ & \\
\hline Education & & & & & & & .038 \\
\hline Illiterate & $4(4.8)$ & $29,814(2.0)$ & $9(3.4)$ & $65,687(3.6)$ & $11(4.7)$ & $50,012(3.2)$ & \\
\hline$\leq$ Elementary school & $11(5.0)$ & $51,261(3.4)$ & $29(11.0)$ & $191,982(10.5)$ & $30(12.9)$ & $188,519(12.1)$ & \\
\hline$\leq$ Middle school & $34(15.5)$ & $230,116(15.3)$ & $45(17.1)$ & 310,905 (16.9) & $37(15.9)$ & $237,626(15.3)$ & \\
\hline$\leq$ High school & 89 (40.6) & $600,422(40.0)$ & $109(41.4)$ & $785,424(42.8)$ & $84(36.2)$ & $562,377(36.1)$ & \\
\hline Colleges & $81(37.0)$ & $589,467(39.3)$ & $71(27.0)$ & $481,001(26.2)$ & $70(30.2)$ & $517,265(33.2)$ & \\
\hline $\begin{array}{l}\text { Monthly average } \\
\text { household income }\end{array}$ & & & & & & & .056 \\
\hline Low & $14(6.4)$ & $85,661(5.7)$ & $26(9.9)$ & $176,229(9.6)$ & $25(10.8)$ & $186,706(12.0)$ & \\
\hline Middle & $64(29.2)$ & $463,187(30.9)$ & 83 (31.6) & $645,415(35.2)$ & $57(24.6)$ & $387,808(24.9)$ & \\
\hline High & $141(64.4)$ & $952,232(63.4)$ & $154(58.6)$ & $1,013,355(55.2)$ & $150(64.7)$ & $981,284(63.1)$ & \\
\hline Smoking & & & & & & & $<.001$ \\
\hline Nonsmoker & $42(19.2)$ & $289,656(19.3)$ & $25(9.5)$ & $146,021(8.0)$ & $18(7.8)$ & $111,054(7.1)$ & \\
\hline Ex-smoker & $84(38.4)$ & $578,843(38.6)$ & $138(52.5)$ & $951,424(51.8)$ & $140(60.3)$ & $946,529(60.8)$ & \\
\hline Current smoker & $93(42.5)$ & $632,581(42.1)$ & $100(38.0)$ & $737,553(40.2)$ & $74(31.9)$ & $498,216(32.0)$ & \\
\hline Physical activity & & & & & & & .006 \\
\hline Yes & $46(21.0)$ & $314,106(20.9)$ & $43(16.3)$ & 283,828 (15.5) & $61(26.3)$ & $425,747(27.4)$ & \\
\hline No & $173(79.0)$ & $1,186,975$ (79.1) & $220(83.7)$ & $1,551,170(84.5)$ & $171(73.7)$ & $1,130,051$ (72.6) & \\
\hline
\end{tabular}

* Number of subjects (\%)

Table 2 Prevalence of MetS components in middle-aged men according to alcohol use behaviors groups

\begin{tabular}{|c|c|c|c|c|c|c|c|}
\hline \multirow[t]{2}{*}{ Variables } & \multicolumn{3}{|c|}{ Normal* } & \multicolumn{2}{|l|}{ Hazardous* } & \multicolumn{2}{|l|}{ Problem* } \\
\hline & $\begin{array}{r}\text { Unweighted } \\
(\mathrm{n}=219)\end{array}$ & Weighted & $\begin{array}{r}\text { Unweighted } \\
(\mathrm{n}=263)\end{array}$ & Weighted & $\begin{array}{r}\text { Unweighted } \\
(\mathrm{n}=232)\end{array}$ & Weighted & \\
\hline $\mathrm{SBP} \geq 130 / \mathrm{DBP} \geq 85 \mathrm{mmHg}$ & & & & & & & $<0.001$ \\
\hline No & $177(80.8)$ & $1,198,534(80.3)$ & $158(60.1)$ & $1,198,534(65.2)$ & $136(58.6)$ & $907,023(58.7)$ & \\
\hline Yes & $42(19.2)$ & $293,853(19.7)$ & $105(39.9)$ & $729,217(39.7)$ & $96(41.4)$ & $639,345(41.3)$ & \\
\hline $\mathrm{FPG}(\mathrm{mg} / \mathrm{dl})$ & & & & & & & 0.011 \\
\hline$<110$ & $197(90.0)$ & $1,355,976(90.9)$ & $220(83.7)$ & $1,518,379(82.6)$ & $185(79.7)$ & $1,240,904(80.2)$ & \\
\hline$\geq 110$ & $22(10.0)$ & $136,411(9.1)$ & $43(16.3)$ & $319,974(17.4)$ & $47(20.3)$ & 305,465 (19.8) & \\
\hline $\mathrm{TG}(\mathrm{mg} / \mathrm{dl})$ & & & & & & & 0.002 \\
\hline$<150$ & $139(63.5)$ & $938,024(62.9)$ & $140(53.2)$ & $989,432(53.8)$ & $101(43.5)$ & $673,118(43.5)$ & \\
\hline$\geq 150$ & $80(36.5)$ & $554,362(37.1)$ & $123(46.8)$ & $848,921(46.2)$ & $131(56.5)$ & $873,250(56.5)$ & \\
\hline HDL cholesterol (mg/dl) & & & & & & & 0.989 \\
\hline$\geq 40$ & $198(90.4)$ & $1,344,251(90.1)$ & $235(89.4)$ & $1,649,815(89.7)$ & $206(88.8)$ & 1,385,960 (89.6) & \\
\hline$<40$ & $21(9.6)$ & $148,136(9.9)$ & $28(10.6)$ & $188,538(10.3)$ & $26(11.2)$ & $160,409(10.4)$ & \\
\hline Waist circumference $(\mathrm{cm})$ & & & & & & & 0.016 \\
\hline$\leq 90$ & $174(79.5)$ & $1,207,352(80.9)$ & $181(68.8)$ & $1,262,234(68.7)$ & $161(69.4)$ & $1,098,043(71.0)$ & \\
\hline$>90$ & $45(20.5)$ & $285,035(19.1)$ & $82(31.2)$ & $576,120(31.3)$ & 71 (30.6) & $448,326(29.0)$ & \\
\hline MetS & & & & & & & 0.009 \\
\hline No & $197(90.0)$ & $1,342,841(81.0)$ & $211(80.2)$ & $1,488,788(81.0)$ & $181(78.0)$ & $1,217,004(78.7)$ & \\
\hline Yes & $22(10.0)$ & $149,546(19.0)$ & $52(19.8)$ & $349,566(19.0)$ & $51(22.0)$ & $329,364(21.3)$ & \\
\hline
\end{tabular}

* Number of subjects (\%)

$\mathrm{SBP}=$ systolic blood pressure; $\mathrm{DBP}=$ diastolic blood pressure; FPG = fasting plasma glucose; $\mathrm{TG}=$ triglyceride; $\mathrm{HDL}=$ high-density lipoprotein 
Table 3 Number of metabolic syndrome components in middle-age male according to alcohol use behavior groups

\begin{tabular}{|c|c|c|c|c|c|c|c|}
\hline \multirow[t]{2}{*}{ Number of risk factors } & \multicolumn{2}{|c|}{ Normal* } & \multicolumn{3}{|c|}{ Hazardous* } & \multirow{2}{*}{$\begin{array}{l}\text { Problem* } \\
\text { Weighted }\end{array}$} & \multirow[t]{2}{*}{$p$} \\
\hline & $\begin{array}{r}\text { Unweighted } \\
(\mathrm{n}=219)\end{array}$ & Weighted & $\begin{array}{r}\text { Unweighted } \\
(\mathrm{n}=263)\end{array}$ & Weighted & $\begin{array}{c}\text { Unweighted } \\
(\mathrm{n}=232)\end{array}$ & & \\
\hline 0 & 87 (39.7) & $592,311(39.7)$ & $70(26.6)$ & $493,767(26.9)$ & $45(19.4)$ & $311,794(20.2)$ & $<<.001$ \\
\hline 1 & $83(37.9)$ & $541,024(36.3)$ & $69(26.2)$ & $473,883(25.8)$ & $72(31.0)$ & $495,033(32.0)$ & \\
\hline 2 & $30(13.7)$ & $209,506(14.0)$ & $72(27.4)$ & $521,138(28.3)$ & $64(27.6)$ & $410,176(26.5)$ & \\
\hline 3 & $21(9.6)$ & $140,423(9.4)$ & $42(16.0)$ & $274,690(14.9)$ & $36(15.5)$ & $229,349(14.8)$ & \\
\hline 4 & $1(0.5)$ & $9,123(0.6)$ & $3(1.1)$ & $51,836(2.8)$ & $12(5.2)$ & $76,715(5.0)$ & \\
\hline 5 & $0(0.0)$ & $0(0.0)$ & $2(0.8)$ & $23,039(1.3)$ & $3(1.3)$ & $23,300(1.5)$ & \\
\hline
\end{tabular}

* Number of subjects (\%)

response relationship existed between alcohol use behaviors and blood pressure $(p<0.001)$, fasting plasma glucose $(p=0.001)$, triglyceride level $(p=0.001)$, waist circumference $(p=0.008)$, and MetS $(p=0.002$; Table 4$)$.

\section{Discussion}

Our study investigated the association between the risk of MetS and alcohol use behaviors in middle-aged South Korean men. In total, $69.3 \%$ of our study population fell within the hazardous and problem groups, which have been deemed injurious to health. Although South Korea's annual alcohol consumption is lower than average, reaching only $8.1 \mathrm{l}$ per year per person, as compared to the OECD average of 9.51 [34], South Korea is one of the most individually intensive drinking nations, with $63.4 \%$ of people consuming $>5$ servings of alcohol in one sitting, as reported in the Global Status Report on Alcohol 2004 [35]. South Koreans prefer to drink soju (Korean distilled spirits), which contains 15-30\% ethanol [36] and makes up $40.4 \%$ of domestic alcohol consumption. Freiberg et al. [24] and Baik and Shin [21] have reported that drinking liquor increases the incidence of MetS to a greater degree than drinking beer or wine. Considering these conditions, policy makers need to intervene on a national level with regard to managing alcohol consumption among middle-aged men.

The prevalence of MetS found in the present study was $19.1 \%$, which is lower than reported for males in the US (24.0\%) and South Korea (27.4\%), but is in agreement with the prevalence of $8-24 \%$ reported in previous studies $[7,8,37]$. The result could be attributable to the fact that the subjects in the present study were limited to middle-aged men.

Our results showed a significant association between the risk of MetS and alcohol use behaviors after accounting for various confounders in middle-aged men. These results are consistent with those of previous studies showing that alcohol consumption exceeding a certain level increases MetS [25,38,39]. Corrao et al. [10] have reported through meta-analysis that drinking $>25$ g/day of alcohol harms health and Alkerwi et al. [40] have reported that favorable metabolic effects seem to be restricted to alcohol consumption of $<40 \mathrm{~g} /$ day among men.

Our study found that alcohol use behaviors were associated with particular components of MetS, including blood pressure, fasting plasma glucose, triglyceride level, and waist circumference, after adjusting for education,

Table 4 Adjusted ORs* and $95 \% \mathrm{Cl}$ of components of metabolic syndrome and metabolic syndrome associated with alcohol use behavior against normal group

\begin{tabular}{|c|c|c|c|c|c|c|c|c|c|c|c|c|}
\hline \multirow[t]{2}{*}{ Variables } & \multirow{2}{*}{$\begin{array}{c}\mathrm{SBP}^{+} \geq 130 / \\
\mathrm{DBP}^{+} \geq 85 \\
\text { Adjusted OR } \\
(95 \% \mathrm{Cl})\end{array}$} & \multirow[t]{2}{*}{$p$} & \multirow{2}{*}{$\begin{array}{c}\mathrm{FPG}^{\ddagger} \geq 110 \\
\text { Adjusted OR } \\
(95 \% \mathrm{Cl})\end{array}$} & \multirow[t]{2}{*}{$p$} & \multirow{2}{*}{$\begin{array}{c}\mathrm{TG}^{\ddagger} \geq 150 \\
\begin{array}{c}\text { Adjusted OR } \\
(95 \% \mathrm{Cl})\end{array}\end{array}$} & \multirow[t]{2}{*}{$p$} & \multirow{2}{*}{$\begin{array}{c}\text { HDL-C }^{\ddagger}<40 \\
\text { Adjusted OR } \\
(95 \% \mathrm{Cl})\end{array}$} & \multirow[t]{2}{*}{$p$} & \multirow{2}{*}{$\begin{array}{c}W^{\S}>90 \\
\begin{array}{c}\text { Adjusted OR } \\
(95 \% \mathrm{Cl})\end{array}\end{array}$} & \multirow[t]{2}{*}{$p$} & \multirow{2}{*}{$\begin{array}{c}\begin{array}{c}\text { Metabolic } \\
\text { syndrome }\end{array} \\
\begin{array}{c}\text { Adjusted OR } \\
(95 \% \mathrm{Cl})\end{array}\end{array}$} & \multirow[t]{2}{*}{$p$} \\
\hline & & & & & & & & & & & & \\
\hline Normal & 1.00 & & 1.00 & & 1.00 & & 1.00 & & 1.00 & & 1.00 & \\
\hline Hazardous & $2.54(1.59-4.06)$ & $<.001$ & $2.15(1.16-3.99)$ & .015 & $1.43(0.94-2.17)$ & .092 & $1.04(0.52-2.07)$ & .917 & $1.93(1.17-3.19)$ & .011 & $2.16(1.24-3.77)$ & .007 \\
\hline Problem & 2.99 (1.83-4.92) & $<.001$ & $2.48(1.42-4.33)$ & .001 & $2.19(1.38-3.47)$ & .001 & $1.07(0.54-2.13)$ & .839 & $1.85(1.17-2.92)$ & .009 & $2.54(1.41-4.58)$ & .002 \\
\hline $\begin{array}{l}P \text { for linear } \\
\text { trend }\end{array}$ & $<.001$ & & .001 & & .001 & & .838 & & .008 & & .002 & \\
\hline
\end{tabular}

$\mathrm{SBP}=$ systolic blood pressure; DBP = diastolic blood pressure; FPG = fasting plasma glucose; TG = triglyceride; HDL-C = high-density lipoprotein cholesterol; WC $=$ waist circumference; $\mathrm{OR}=$ odds ratio; $\mathrm{Cl}=$ confidence interval.

* ORs were adjusted for education, smoking, and physical activity.

${ }^{\dagger}$ Unit: $\mathrm{mmHg}$

‡ Unit: $\mathrm{mg} / \mathrm{dL}$

$\S$ Unit: $\mathrm{cm}$ 
smoking, and physical activity. This means that increased alcohol consumption brings with it an increase in the risk of hypertension, impaired fasting glucose levels, high triglycerides, and abdominal obesity.

Excessive consumption of alcohol can lead to hypertension [23,39]. Although alcohol decreases blood pressure transiently during the first 2 hours after consumption, it subsequently increases blood pressure considerably [41]. A study by McFadden et al. [41] using meta-analysis reported that daily alcohol intake increased systolic blood pressure by $2.7 \mathrm{mmHg}$ and diastolic blood pressure by $1.4 \mathrm{mmHg}$. Yoon et al. [23] also reported that alcohol consumption $\geq 30 \mathrm{~g} / \mathrm{d}$ increased blood pressure. Consistent with our results, Baliunas et al. [42] and Chrysohoou et al. [39] reported that moderate alcohol consumption decreases the risk of diabetes, whereas excessive alcohol consumption increases the risk. Baliunas et al [42] also reported that alcohol consumption $\geq 60 \mathrm{~g} / \mathrm{d}$ increased this risk. In addition, higher than moderate alcohol consumption has been found to increase the density of triglycerides in the bloodstream [39]. Yoon et al. [23] also reported that alcohol consumption $\geq 30 \mathrm{~g} / \mathrm{d}$ increased the density of triglycerides. However, we observed a non-significant change in the risk of low HDL cholesterol in the hazardous and problem groups, which conflicts with previous studies showing that the level of HDL cholesterol increases with both excessive and moderate quantities of alcohol consumption[23,43-45]. The results of this study are consistent with those of Fan et al. [25], who showed that daily alcohol consumption above US dietary guidelines increased the risk of low HDL-cholesterol, although their study also failed to achieve statistical significance on this parameter. Duncan et al. [46] have reported that moderate alcohol consumption decreases waist circumference, whereas excessive quantities modulate the concentration of sex hormones, causing abdominal obesity $[25,36,46]$. We likewise found that men in the hazardous and problem groups showed an increase in the risk of abdominal obesity, as compared to the normal group.

Strengths of this study included the use of a large pool of population-based data, and the use of established assessment methods such as AUDIT. Nevertheless, this study was limited in several dimensions. First, given the cross-sectional design, we could not draw any causal inference regarding the associations found. Second, we could not subdivide the alcohol use behaviors of the normal group, making it impossible to examine the association between light alcohol use and MetS and MetS components. The J-shaped association was not confirmed in the relationship between alcohol use and MetS. However, given that the purpose of this study was to investigate the association between alcohol use behaviors and the risk of MetS, the analytical model of our study was adequate. Third, the study results were acquired by analysis of data from the second year of KNHANES IV (2008) and could be generalized to the whole South Korean population. However, because data that were missing important analytical values were excluded from the present study, the present study encountered limitations resulting from the failure to secure a large enough sample as well as limitations in the generalizability of the study findings to all middleaged South Korean men. Also, the exclusion of subjects with missing values could have introduced selection bias into the study. Therefore, careful interpretation of the present study results is required, especially considering that the study subjects with problematic alcohol use behaviors were found to comprise $69.3 \%$ of all subjects (hazardous alcohol use, 37.5\%; problematic alcohol use, $31.8 \%)$. These results should be confirmed through future studies. Our study did not consider eating habits and family history, both of which are important risk factors for MetS $[43,47]$. Further studies are warranted to examine these factors.

\section{Conclusions}

The present study investigated the relationship between alcohol use behaviors and the risk of MetS in middle-aged men in South Korea using the secondyear data of KNHANES IV. In conclusion, our study found that excessive alcohol use behaviors increased the risk of hypertension, diabetes, dyslipidemia, abdominal obesity, and MetS after adjustment for education, smoking, and physical activity. Additionally, a dose-response relationship existed between alcohol use behaviors and blood pressure, fasting plasma glucose, triglyceride level, waist circumference, and MetS. Considering the rising rate of alcohol consumption and heavy drinking at single sittings, a culture of less risky alcohol consumption must be established to promote health among middle-aged men.

\section{Author details}

${ }^{1}$ National Evidence-based Healthcare Collaborating Agency, Seoul, South Korea. ${ }^{2}$ Department of Nursing, Eulji University, Seoul, South Korea. ${ }^{3}$ National Strategic Coordinating Center for Clinical Research, Seoul, South Korea.

${ }^{4}$ Cardiac \& Vascular Center, Samsung Medical Center, Seoul, South Korea.

\section{Authors' contributions}

SKC conceived of the study and participated in its design and coordination. JK participated in the design and coordination of the study and drafted the manuscript. KK participated in the study design and performed the statistical analysis. JRM helped to draft the manuscript. All authors read and approved the final manuscript.

\section{Competing interests}

The authors declare that they have no competing interests.

Received: 24 January 2011 Accepted: 22 June 2011

Published: 22 June 2011 
References

1. Evandrou M, Glaser K, Henz U: Multiple role occupancy in midlife: balancing work and family life in Britain. The Gerontologist 2002, 42(6):781-789

2. Hong SJ: Problems of industralization in Korea: Changes in Korean identity in industrialization Seoul: Nanam; 1990

3. Lee EA, Chung HJ: Individual and family variables related to middle-aged men's psychological crisis. Korea Association of Family Relations 2007, 12(2):301-329.

4. Lakka HM, Laaksonen DE, Lakka TA, Niskanen LK, Kumpusalo E, Tuomilehto J, Salonen JT: The metabolic syndrome and total and cardiovascular disease mortality in middle-aged men. JAMA 2002, 288(21):2709-2716

5. Isomaa B, Almgren P, Tuomi T, Forsen B, Lahti K, Nissen M, Taskinen MR, Groop L: Cardiovascular morbidity and mortality associated with the metabolic syndrome. Diabetes Care 2001, 24(4):683-689.

6. Meigs JB: Invited commentary: Insulin resistance syndrome? Syndrome $\mathrm{X}$ ? Multiple metabolic syndrome? A syndrome at all? Factor analysis reveals patterns in the fabric of correlated metabolic risk factors. Am J Epidemiol 2000, 152(10):908-911, Discussion 912

7. Zimmet P, Magliano D, Matsuzawa Y, Alberti G, Shaw J: The metabolic syndrome: a global public health problem and a new definition. $J$ Atheroscler Thromb 2005, 12(6):295-300.

8. In-depth analysis report of the Third Korea National Health and Nutrition Examination Survey (KNHANES?) - Health examination part Seoul: Korea Center for Disease Control and Prevention; 2007.

9. Gaziano JM, Buring JE, Breslow JL, Goldhaber SZ, Rosner B, VanDenburgh M Willett W, Hennekens $\mathrm{CH}$ : Moderate alcohol intake, increased levels of high-density lipoprotein and its subfractions, and decreased risk of myocardial infarction. N Engl J Med 1993, 329(25):1829-1834.

10. Corrao G, Bagnardi V, Zambon A, La Vecchia C: A meta-analysis of alcohol consumption and the risk of 15 diseases. Prev Med 2004, 38(5):613-619.

11. Bagnardi V, Blangiardo M, La Vecchia C, Corrao G: A meta-analysis of alcohol drinking and cancer risk. Br J Cancer 2001, 85(11):1700-1705.

12. Dyer AR, Stamler J, Paul O, Berkson DM, Shekelle RB, Lepper MH, McKean $H$, Lindberg HA, Garside D, Tokich T: Alcohol, cardiovascular risk factors and mortality: the Chicago experience. Circulation 1981, 64(3 Pt 2):III 20-27.

13. Oh SW: Effects of alcohol on obesity and metabolic syndrome. Korean Journal of Obesity 2009, 18(1):1-7.

14. Hong AR, Lee $\mathrm{KS}$, Lee $\mathrm{SY}, \mathrm{Yu} \mathrm{JH}$ : Association of current and past smoking in men with metabolic syndrome. J Prev Med Public Health 2009, 42(3):160-164

15. Wannamethee SG, Shaper AG, Whincup PH: Modifiable lifestyle factors and the metabolic syndrome in older men: effects of lifestyle changes. $J$ Am Geriatr Soc 2006, 54(12):1909-1914.

16. Oh SW, Yoon YS, Lee ES, Kim WK, Park C, Lee S, Jeong EK, Yoo T: Association between cigarette smoking and metabolic syndrome: the Korea National Health and Nutrition Examination Survey. Diabetes Care 2005, 28(8):2064-2066.

17. Kim MH, Park JS, Jung JW, Byun KW, Kang KS, Lee YS: Daidzein supplementation prevents non-alcoholic fatty liver disease through alternation of hepatic gene expression profiles and adipocyte metabolism. Int J Obes (Lond) 2010

18. Ford ES, Kohl HW III, Mokdad AH, Ajani UA: Sedentary behavior, physical activity, and the metabolic syndrome among US adults. Obes Res 2005, 13(3):608-614

19. Rennie KL, McCarthy N, Yazdgerdi S, Marmot M, Brunner E: Association of the metabolic syndrome with both vigorous and moderate physical activity. Int J Epidemiol 2003, 32(4):600-606.

20. Riccardi G, Rivellese AA: Dietary treatment of the metabolic syndromethe optimal diet. Br J Nutr 2000, 83(S1):143-148.

21. Baik I, Shin C: Prospective study of alcohol consumption and metabolic syndrome. Am J Clin Nutr 2008, 87(5):1455-1463.

22. Fan AZ, Russell M, Dorn J, Freudenheim JL, Nochajski T, Hovey K, Trevisan M: Lifetime alcohol drinking pattern is related to the prevalence of metabolic syndrome. The Western New York Health Study (WNYHS). Eur J Epidemiol 2006, 21(2):129-138.

23. Yoon YS, Oh SW, Baik HW, Park HS, Kim WY: Alcohol consumption and the metabolic syndrome in Korean adults: the 1998 Korean National Health and Nutrition Examination Survey. Am J Clin Nutr 2004, 80(1):217-224.
24. Freiberg MS, Cabral HJ, Heeren TC, Vasan RS, Curtis Ellison R: Alcohol consumption and the prevalence of the metabolic syndrome in the US: a cross-sectional analysis of data from the Third National Health and Nutrition Examination Survey. Diabetes Care 2004, 27(12):2954-2959.

25. Fan AZ, Russell $M$, Naimi $T$, Li $Y$, Liao $Y$, Jiles $R$, Mokdad $A H$ : Patterns of alcohol consumption and the metabolic syndrome. J Clin Endocrinol Metab 2008, 93(10):3833-3838.

26. Babor TF, Higgins-Biddle JC, Saunders JB, Monteiro MG: AUDIT: The alcohol use disorders identification test - Guidelines for use in primary care. Geneva: World Health Organization; 22001.

27. Guidline for use of The Fourth Korean National Health and Nutrition Examination Survey (KNHANES IV)'s raw data Seoul: Ministry of Health \& Welfare, Korea Center for Disease Control and Prevention; 2010.

28. Lee GO, Park JU: Final Report of the Fourth Korean National Health and Nutrition Examination Survey (KNHANES IV)'s Sampling Frame Seoul: Korea Survey \& Research Society; 2007.

29. Statistics Korea: Fourth Quarter 2008 and Annual Household Trends. [http://kostat.go.kr/portal/korea/kor_nw/2/1/index.board?bmode=read $\& b S e q=\& a S e q=66137 \&$ page $\mathrm{No}=1 \&$ row $\mathrm{Num}=10 \&$ navCount=10\&currPg $=$ \&sTarget=title\&sTxt=\%EA\%B0\%80\%EA\%B3\%84\%EC\%88\%98\%EC\%A7\%80\%EB \%8F\%99\%ED\%96\%A5].

30. Ministry for Heatlh and Welfare: Minimum Cost of Living in 2008.[http:// www.mw.go.kr/front/al/sal0301 vw.jsp?PAR_MENU_ID=04\&MENU_ID=0403 \&page $=1 \& B O A R D \_I D=140 \& B O A R D \_F L A G=\& C O N T \_S E Q=41953$ $\&$ SEARCHKEY $=$ TITLE\&SEARCHVALUE $=\& C R E A T E ~ D A T E 1=\& C R E A T E ~ D A T E 2=]$.

31. World Health Organization: Global recommendations on Physical Activity for Heatlh.[http://www.who.int/dietphysicalactivity/ factsheet_recommendations/en/index.html].

32. Antonopoulos S: Third report of the National Cholesterol Education Program (NCEP) expert panel on detection, evaluation, and treatment of high blood cholesterol in adults (Adult Treatment Panel III) final report Circulation 2002, 106:3143-3421.

33. Inoue S, Zimmet P: The Asia-Pacific perspective: Redefining obesity and its treatment. In Health Communications Australia Pty Limited on Behalf of the Steering Committee. Edited by: T-P. Sydney: World Health Organization Western Pacific Region, International Association for the Study of Obesity, International Obesity Task Force; 2000:

34. Korea Institutee for Health and Social Affairs: Health and Social Statistics. [http://www.kihasa.re.kr/html/jsp/info/info_03_view.jsp? currPage $=6 \& d 1=1 \& d 2=3 \& d 3=1 \&$ seq $=19 \&$ sg $=\&$ key $=]$.

35. Global Status Report on Alcohol 2004 Geneva: World Health Organizationi; 2004

36. KIm TH: Domestic Alcohol market trend in 2010. Trends of liquor 2010, 1:18-25.

37. Ford ES, Giles WH, Dietz WH: Prevalence of the metabolic syndrome among US adults. JAMA 2002, 287(3):356-359.

38. Athyros VG, Liberopoulos EN, Mikhailidis DP, Papageorgiou AA, Ganotakis ES, Tziomalos K, Kakafika Al, Karagiannis A, Lambropoulos S, Elisaf M: Association of drinking pattern and alcohol beverage type with the prevalence of metabolic syndrome, diabetes, coronary heart disease, stroke, and peripheral arterial disease in a Mediterranean cohort. Angiology 2008, 58(6):689-697.

39. Chrysohoou C, Panagiotakos DB, Pitsavos C, Skoumas J, Toutouza M, Papaioannou I, Toutouzas PK, Stefanadis C: Effects of chronic alcohol consumption on lipid levels, inflammatory and haemostatic factors in the general population: the 'ATIICA' Study. Eur J CardiovasC Prev Rehabil 2003, 10(5):355-361.

40. Alkerwi A, Boutsen M, Vaillant M, Barre J, Lair ML, Albert A, Guillaume M, Dramaix M: Alcohol consumption and the prevalence of metabolic syndrome: a meta-analysis of observational studies. Atherosclerosis 2009 204(2):624-635.

41. McFadden CB, Brensinger CM, Berlin JA, Townsend RR: Systematic review of the effect of daily alcohol intake on blood pressure. Am J Hypertens 2005, 18(2):276-286.

42. Baliunas DO, Taylor BJ, Irving H, Roerecke M, Patra J, Mohapatra S, Rehm J: Alcohol as a risk factor for type 2 diabetes. Diabetes Care 2009, 32(11):2123-2132.

43. Lee WY, Jung CH, Park JS, Rhee EJ, Kim SW: Effects of smoking, alcohol, exercise, education, and family history on the metabolic syndrome as defined by the ATP III* 1. Diabetes Res Clin Pract 2005, 67(1):70-77. 
44. Linn S, Carroll M, Johnson C, Fulwood R, Kalsbeek W, Briefel R: High-density lipoprotein cholesterol and alcohol consumption in US white and black adults: data from NHANES II. Am J Public Health 1993, 83(6):811-816.

45. Rimm EB, Williams P, Fosher K, Criqui M, Stampfer MJ: Moderate alcohol intake and lower risk of coronary heart disease: meta-analysis of effects on lipids and haemostatic factors. Br Med J 1999, 319(7224):1523-1528.

46. Duncan BB, Chambless LE, Schmidt MI, Folsom AR, Szklo M, Crouse JR III, Carpenter MA: Association of the waist-to-hip ratio is different with wine than with beer or hard liquor consumption. Am J Epidemiol 1995, 142(10):1034-1038

47. Djousse L, Padilla H, Nelson TL, Gaziano JM, Mukamal KJ: Diet and metabolic syndrome. Endocr Metab Immune Disord Drug Targets 2010, 10(2):124-137.

\section{Pre-publication history}

The pre-publication history for this paper can be accessed here: http://www.biomedcentral.com/1471-2458/11/489/prepub

doi:10.1186/1471-2458-11-489

Cite this article as: Kim et al: Alcohol use behaviors and risk of metabolic syndrome in South Korean middle-aged men. BMC Public Health 2011 11:489.

\section{Submit your next manuscript to BioMed Central} and take full advantage of:

- Convenient online submission

- Thorough peer review

- No space constraints or color figure charges

- Immediate publication on acceptance

- Inclusion in PubMed, CAS, Scopus and Google Scholar

- Research which is freely available for redistribution

Submit your manuscript at www.biomedcentral.com/submit 